\title{
Desafíos de la Odontología Frente a la Pandemia del COVID-19
}

\author{
Challenges of Dentistry in the Face of the Covid-19 Pandemic
}

\author{
Mariella Chávez Tuñón \& Carmen Castro-Ruiz
}

CHAVEZ, T. M. \& CASTRO-RUIZ, C. Desafíos de la Odontología frente a la Pandemia del COVID-19. Int. J. Odontostomat, 14(3):325-326, 2020.

RESUMEN: La emergencia sanitaria mundial, originada debido a la Pandemia del Covid -19, ha modificado nuestras costumbres y ha desnudado las carencias de un fragmentado sistema de salud en latinoamérica. Es crucial en estos momentos, para preservar la odontología y el bienestar de los pacientes, que a través de los ministerios de salud y colegios profesionales se tomen medidas de emergencia para ayudar al odontólogo con los altos costos de mantener la seguridad del personal y la de los pacientes en su práctica profesional.

PALABRAS CLAVE: COVID-19, SARS-CoV-2, dental, odontólogo.

\section{INTRODUCCIÓN}

La emergencia sanitaria mundial, originada debido a la Pandemia del Covid-19 (SARS-CoV-2), ha modificado nuestras costumbres y ha desnudado las carencias de un fragmentado sistema de salud en latinoamérica.

El servicio que brinda el odontólogo es indispensable para la salud del ser humano, siendo que las enfermedades de la cavidad oral afectan de forma física y psicológica, pudiendo las más graves complicaciones atentar con la vida de los pacientes.

En el contexto de esta pandemia, los odontólogos formamos parte del grupo de profesionales de la salud con alto riesgo, debido a que trabajamos en la cavidad oral, en íntima relación con la zona nasofaríngea, a menos del metro de distancia sugerido para evitar el contagio (Bourouiba, 2020; Lauer et al., 2020; Peng et al., 2020).

Algunos estudios han demostrado que los aerosoles (partículas de menos de 50 micrómetros de diámetro) de patógenos como el causante del covid19 , pueden permanecer en el aire por un periodo prolongado y tienen mayor potencial de transmitir infecciones antes que se adhieran a superficies (Harrel \&
Molinari, 2004). Esto se potencia en los procedimientos propios de la atención odontológica que generan aerosoles y salpicaduras donde tanto el odontólogo, cómo el personal asistencial, incluídos pacientes, están expuestos al contagio (Harrel \& Molinari).

En caso de los odontólogos independientes, que en Perú son la mayoría, siendo sólo el $12 \%$ dependientes del estado (Dirección General de Personal de la Salud, 2019), son ellos mismos los que asumen los altos costos de la práctica dental.

Sabemos que ante la emergencia sanitaria actual se ha establecido cuarentena en la mayoría de países a nivel mundial, y que sólo es posible atender situaciones odontológicas de emergencia, pero ¿qué va a pasar, cuando se levante esta restricción, y se pueda realizar la atención de los pacientes con mayor regularidad?

En una economía tan golpeada cómo la nuestra, conseguir equipos de protección a sobre precio, podría generar que sea mayor la inversión en protectores que el costo de la atención, pudiendo llevar a los profesionales a no utilizarlos o a reutilizarlos de forma indebida. 


\section{CONCLUSIONES}

Es crucial en estos momentos, que a través de los ministerios de salud y colegios profesionales se tomen medidas para ayudar al odontólogo en su práctica profesional con los altos costos que demanda el mantener la seguridad del personal y la de los pacientes; teniendo en consideración además, que posteriormente todos los involucrados, van a entrar en contacto con otras personas como sus familias, colegas, etc.

Es necesario, asegurar un precio justo y el abastecimiento permanente de batas impermeables, guantes, gorro, botas, mascarillas adecuadas, protectores faciales y gafas de protección cómo mínimo, para poder cumplir con los protocolos adecuados de bioseguridad y, de esta manera, poder realizar la atención odontológica con los stándares recomendados internacionalmente (Sociedad Española de Cirugía Oral y Maxilofacial y de Cabeza y Cuello, 2020).

CHAVEZ, T. M. \& CASTRO-RUIZ, C. Challenges of dentistry in the face of the COVID-19 pandemic. Int. J. Odontostomat, 14(3):325-326, 2020.

ABSTRACT: The worlwide sanitary emergency caused by the Covid-19 Pandemy, has modified our costums and has showed big deficiencies in the latinoamerican health system. At present time, is crucial for the dentistry field and patients, that through the goverment Health Ministeries and Professionals organisms, emergency meausures be taken to help the dentist with the high cost of keeping the security of his personnel and patients in the dental practice during this pandemy.

KEY WORDS: COVID-19, SARS-CoV-2, dental, dentist.

\section{REFERENCIAS BIBLIOGRÁFICAS}

Bourouiba, L. Turbulent gas clouds and respiratory pathogen emissions: potential implications for reducing transmission of COVID-19. JAMA, 2020. DOI: https://www.doi.org/10.1001/ jama.2020.4756

Dirección General de Personal de la Salud. Compendio Estadístico: Informe de Recursos Humanos del Sector Salud Perú 20132018. Lima, Dirección General de Personal de la Salud, Observatorio de Recursos Humanos en Salud, Ministerio de Salud, República del Perú, 2019. Disponible en: https://cdn.www.gob.pe/ uploads/document/file/471227/611006664466105977201912317797-v1u7tn.pdf
Harrel, S. K. \& Molinari, J. Aerosols and splatter in dentistry: a brief review of the literature and infection control implications. J. Am. Dent. Assoc., 135(4):429-37, 2004.

Lauer, S. A.; Grantz, K. H.; Bi, Q.; Jones, F. K.; Zheng, Q.; Meredith, H. R.; Azman, A. S.; Reich, N. G. \& Lessler, J. The incubation period of coronavirus disease 2019 (COVID-19) from publicly reported confirmed cases: estimation and application. Ann. Intern. Med., 2020. DOI: https://www.doi.org/10.1101/ 2020.02.02.20020016

Peng, X.; Xu, X.; Li, Y.; Cheng, L.; Zhou, X. \& Ren, B. Transmission routes of $2019-\mathrm{nCoV}$ and controls in dental practice. Int. J. Oral Sci.; $12: 9,2020$.

Sociedad Española de Cirugía Oral y Maxilofacial y de Cabeza y Cuello. Recomendaciones SECOMCYC en Relación con la Cirugía y COVID-19. Comunicado. Madrid, Sociedad Española de Cirugía Oral y Maxilofacial y de Cabeza y Cuello, 2020. Disponible en: http://facme.es/wp-content/uploads/2020/03/1.-RECOMENDACIONES-GENERALES-SECOMCYC-ACTUACIONCOVID-19.pdf

Dirección para correspondencia

Carmen Castro Ruiz

Mg. en Periodoncia

Escuela de Estomatología

Universidad Científica del Sur

Lima

PERÚ

Email: dra.castroruiz@mail.com

Recibido : 24-04-2020

Aceptado: 25-04-2020 